\title{
Relation of Helicobacter pylori infection and coronary heart disease
}

\author{
Michael A Mendall, Patrick M Goggin, Nicola Molineaux, Joanna Levy, T Toosy, \\ David Strachan, A John Camm, Timothy C Northfield
}

Department of

Medicine, St Georges

Hospital Medical

School, Cranmer

Terrace, Tooting,

London

M A Mendall

P M Goggin

N Molineaux

J Levy

T C Northfield

Department of

Cardiological Science

A J Camm

Department of Public

Health Sciences

D Strachan

The Practice, Park

Road, Wallington,

Surrey

$T$ Toosy

Correspondence to

Dr Michael A Mendall,

Department of Medicine, $S t$

Georges Hospital Medical

School, Cranmer Terrace,

Tooting, London

SW17 ORE.

Accepted for publication

4 January 1994

\begin{abstract}
Background-There is evidence suggesting that early life experience may influence adult risk of coronary heart disease (CHD). Chronic bacterial infections have been associated with CHD.
\end{abstract}

Objective-To determine whether Helicobacter pylori, a childhood acquired chronic bacterial infection, is associated with an increased risk of coronary heart disease in later life.

Design-Case-control study controlling for potential confounding variables with an opportunistically recruited control group.

Subjects-111 consecutive cases with documented CHD were recruited from a cardiology clinic and 74 controls from a general practice health screening clinic. All were white men aged 45-65.

Methods-Serum was analysed for the presence of $\boldsymbol{H}$ pylori specific IgG antibodies by ELISA ( $98 \%$ sensitive and $94 \%$ specific for the presence of infection).

Results $-59 \%$ of the cases and $39 \%$ of the controls were seropositive for $H$ pylori (odds ratio $2 \cdot 28, \chi^{2} 7 \cdot 35, p=0 \cdot 007$ ). After adjustment by multiple logistic regression for age, cardiovascular risk factors, and current social class, the effect of $H$ pylori was little altered (odds ratio $2 \cdot 15, \mathrm{p}$ $=0.03)$. Further adjustment for various features of the childhood environment known to be risk factors for $H$ pylori infection only slightly weakened the association (odds ratio 1.9). H pylori seropositivity was not related to the level of risk factors in the control population.

Conclusion-In this pilot study the association of adult coronary heart disease with $H$ pylori seropositivity suggests that the early childhood environment may be important in determining the risk of CHD in adult life. The association needs confirmation in other better designed studies. If $H$ pylori itself is responsible for the association, then this is of great potential importance as the infection is treatable.

(Br Heart f 1994;71:437-439)

Evidence suggests that childhood deprivation may influence adult risk of coronary heart disease (CHD). ${ }^{1}$ Chronic bacterial infections have also been linked to the risk of CHD in adults. ${ }^{23}$ Helicobacter pylori is a chronic bacterial infection of the stomach that is usually acquired in childhood. ${ }^{4}$ It causes an active gastritis in all subjects infected with it and is strongly associated with gastric cancer and peptic ulcer disease, conditions that occur more commonly than by chance in association with CHD. ${ }^{56}$ Acquisition of $\mathrm{H}$ pylori is associated with poverty. ${ }^{4}$ This chronic bacterial infection may be a causative agent that explains part of the link between childhood poverty and adult $\mathrm{CHD}$.

We used a case-control comparison to investigate whether $H$ pylori infection was associated with adult $\mathrm{CHD}$. We also studied possible associations of $H$ pylori infection with cardiovascular risk factors in the control population.

\section{Patients and methods}

PATIENTS

We studied men aged $45-65$. The controls came from a single general practice screening clinic and the cases from a series of consecutive patients referred to the cardiology clinic of a local teaching hospital with angiographically confirmed CHD (stenosis $>70 \%$ in one coronary artery). Potential controls were excluded if they had a firm diagnosis of $\mathrm{CHD}$.

\section{METHODS}

All subjects completed a questionnaire and 10 $\mathrm{ml}$ of serum was drawn and stored at $-20^{\circ} \mathrm{C}$. Blood pressure was measured in the general practice when the patient was seated. One observer used the same mercury sphygmomanometer throughout the study.

We measured $H$ pylori specific IgG antibody titres by an in-house enzyme linked immunoadsorbent assay (ELISA) in duplicate, using a partially purified antigen as described previously. ${ }^{4}$ Titres were dichotomised into seropositive and seronegative according to a previously chosen cut off value, which had a sensitivity of $98 \%$ and a specificity of $94 \%$. Non-fasting total serum cholesterol concentration was measured in the men attending the general practice clinic.

Results were analysed by multiple logistic regression using GLIM ${ }^{\top}$ and multiple regression using the GLM proceedure in $S A S$. In the logistic regression models, age was grouped into four categories $(45-49,50-54$, 55-59, 60-65) and current social class was grouped into six categories according to the Registrar-General's 1980 classification. Smoking habit was grouped by age at starting smoking (never, <15, 15-19, 20+) and 
Odds ratio for coronary heart disease among men who were seropositive for $H$ pylori

\begin{tabular}{|c|c|c|c|}
\hline Effect of $H$ pylori adjusted for: * & Odds ratio $(95 \%$ CI) & $\chi^{2}(1 d f)$ & p Value \\
\hline Unadjusted & $2 \cdot 28(1.25$ to $4 \cdot 15)$ & $7 \cdot 35$ & 0.007 \\
\hline Age, and risk factors $\dagger$ & $2 \cdot 26(1 \cdot 15$ to $4 \cdot 44)$ & $5 \cdot 71$ & 0.02 \\
\hline $\begin{array}{l}\text { Age, risk factors, and current } \\
\text { social class }\end{array}$ & $2 \cdot 15(1 \cdot 07$ to $4 \cdot 29)$ & $4 \cdot 73$ & 0.03 \\
\hline $\begin{array}{l}\text { Age, risk factors, current social } \\
\text { class and father's occupation }\end{array}$ & $2 \cdot 08(1.03$ to $4 \cdot 20)$ & $4 \cdot 23$ & $0 \cdot 04$ \\
\hline $\begin{array}{l}\text { Age, risk factors, current social } \\
\text { class and father's occupation, } \\
\text { housing density, and hot water } \\
\text { supply in the childhood home }\end{array}$ & $1.90(0.91$ to 3.97$)$ & $2 \cdot 97$ & 0.09 \\
\hline
\end{tabular}

^ Adjusted by multiple logistic regression.

†Smoking history, age at starting smoking, lifetime cigarette consumption, history of high blood pressure, history of diabetes. lifetime cigarette consumption (pack-years) was estimated from the duration of smoking and usual daily consumption. History of high blood pressure, history of diabetes, and father's occupation (manual, non-manual) were treated as dichotomous variables. The number of persons per room (excluding kitchen and bathroom) was used as a quantitative index of housing density in childhood.

\section{Results}

There were 111 cases (median age 56), of CHD of whom $20 \%$ had had a myocardial infarction with no angina, $51 \%$ a myocardial infarction followed by angina, and $29 \%$ angina only. Thirteen of the CHD cases had had coronary artery bypass grafts. The 74 controls (median age 53) included $26(35 \%)$ who were invited to attend the health screening clinic by post, $20(27 \%)$ were invited to attend by their general practitioner after another consultation, and $28(38 \%)$ who were selfreferrals.

Sixty $\operatorname{six}(59 \%)$ of the cases and $29(39 \%)$ of controls were seropositive for $H$ pylori. The table shows the odds ratio for the association of $H$ pylori with CHD after adjustment for various cardiovascular risk factors (smoking history, age at starting smoking, lifetime cigarette consumption, history of high blood pressure, history of diabetes), and features of current and childhood socioeconomic conditions. The effect of $H$ pylori on coronary heart disease was not diminished by controlling for conventional risk factors. The effect was only slightly diminished by controlling for current social class and father's occupation. Further adjustment for lack of a hot water supply and childhood crowding, factors that were strongly associated with $H$ pylori infection, ${ }^{4}$ altered the odds ratio for $H$ pylori very little though it then became of borderline statistical significance $(0 \cdot 1>\mathrm{p}>0.05)$.

The relation between $H$ pylori seropositivity and age adjusted risk factors was examined. Controls who were seropositive for $H$ pylori had similar mean (SEM) cholesterol concentrations $(6.09(0.28) v 5.75(0.23) \mathrm{mmol} / \mathrm{l}, 41$ subjects only), smoking habits $(21 \cdot 3(4 \cdot 4) v$ $19.6(3.5)$ pack years), blood pressure (systolic $132(3.0) v 134(2.4) \mathrm{mm} \mathrm{Hg}$ and diastolic $83.1(1 \cdot 7) v 86.2(1.4) \mathrm{mm} \mathrm{Hg}$ ), and body mass index $(26.6(0.7)$ v $27 \cdot 1(0.5)$ $\mathrm{kg} / \mathrm{m}^{2}$ ), as the seronegative controls.

\section{Discussion}

In this study $H$ pylori infection was related to adult CHD independently of smoking history, age at starting smoking, lifetime cigarette consumption, history of diabetes, and high blood pressure. Adult social class and other factors associated with childhood poverty caused only minor confounding of the effect of $H$ pylori. In addition there was no strong relation between $H$ pylori infection and conventional risk factors in the control population. Even if $H$ pylori is only acting as a marker of childhood poverty, this is evidence supporting a link between early living conditions and adult risk of CHD.

This was a pilot study that used an opportunistically recruited control group and an outpatient case series and as such is liable to the effects of bias in both the control and case groups. The $H$ pylori seroprevalence of the control group is comparable to other published figures for British men of a similar age group. ${ }^{8}$ White patients with dyspepsia (mean age 48) directly referred to St Georges Hospital for endoscopy had a similar rate of infection $(186 / 418=44 \%)$ as our controls, ${ }^{9}$ and most series have reported higher rates of infection in dyspeptic subjects undergoing endoscopy than in the general population.

The effect of selection bias among the cases is harder to assess. Bias could have arisen if subjects infected by $H$ pylori were over represented among the cases, perhaps because they were referred more commonly for investigation in the cardiac clinic than non-infected subjects with CHD. Dyspepsia related to $H$ pylori infection might have been misdiagnosed as cardiac pain. However, while $H$ pylori is undoubtedly related to peptic ulcer disease, its relation with non-ulcer dyspepsia is weaker. ${ }^{10}$ In our study, subjects with CHD had previously consulted their general practitioner with indigestion or heartburn more often than the controls, but this proportion was similar in patients with CHD who were seropositive and those who were seronegative for $H$ pylori infection ( $45 \% v 41 \%)$. Also there was no significant difference in the rates of $H$ pylori infection between the three subgroups of cases-myocardial infarction with no subsequent angina $(60 \%)$, myocardial infarction and angina $(54 \%)$, and angina with no previous infarction $(68 \%)$-suggesting that the presence of infection was unrelated to the reason for referral. Furthemore, 6/9 cases of CHD recruited from the general practice health screening clinic were seropositive for $H$ pylori, a rate similar to that seen in the cases recruited from the hospital clinic. Though a bias in case ascertainment cannot be discounted, it is unlikely that it could wholly explain the association that we observed between $H$ pylori and CHD.

Though $H$ pylori may simply be a marker for poverty in childhood, because seropositivity remained a risk factor for CHD after adjustment for other indices of childhood circumstances it may have an independent causal effect. $H$ pylori could influence the development of CHD through the systemic effects of 
chronic active inflammation in a large viscus. Circulating concentrations of lipid peroxides, which are also associated with cardiovascular risk, were raised in patients with gastritis associated with $H$ pylori. ${ }^{11}$ In addition a low grade acute phase response could be induced by tumour necrosis factor alpha and interleukin6 - both of which have been found in the gastric mucosa of infected individuals. ${ }^{12}$ Fibrinogen and apolipoprotein (a) are both acute phase proteins.

The association between $H$ pylori and CHD reported here needs confirmation by other more rigorously controlled epidemiological studies. We have recently started case-control and cross sectional population studies of the relation of $H$ pylori to $\mathrm{CHD}$ and its major risk factors. A causal link between $H$ pylori and CHD would be of major public health importance because the infection can be eradicated with a single course of antibiotics with little chance of reinfection. ${ }^{13}$

1 Elford J, Whincup P, Shaper A G. Early life experience and adult cardiovascular disease: Longitudinal and casecontrol studies. Int $\mathcal{F}$ Epidemiol 1991;20:833-44.
2 Mattila $\mathrm{K}$ J, Nieminen $\mathrm{M} \mathrm{S}$, Valtonen $\mathrm{V} \mathrm{V}$, et al. Association between dental health and acute myocardial infarction. Br Med f 1989;298:779-82.

3 Saikku P, Mattila K, Nieminen M S, et al. Serological evidence of an association of a novel chlamydia, TWAR, with chronic coronary heart disease and acute myocarwith chronic coronary heart disease
dial infarction. Lancet 1988;ii:983-6.

4 Mendall M A, Goggin P M, Molineaux N, Levy J, Toosy T, Strachan D, Northfield T C. Association between childhood living conditions and Helicobacter pylori seropositivity in adult life. Lancet 1992;i:896-7.

5 Sonnenburg A. Concordant occurrence of gastric and hypertensive diseases. Gastroenterology 1988;95:42-8.

6 Langman M J S, Cooke A R. Gastric and duodenal ulce and their associated diseases. Lancet 1976;i:680-3.

7 Baker RJ, Nelder JA. The GLIM system manual, release 3 Oxford: Numerical Alogorithms Group, 1978.

8 The EUROGAST Study Group. An international association between Helicobacter pylori infection and gastric cancer. Lancet 1993;341:1359-62.

9 cancer. Lancet 1993;341:1359-62. Levy J, Badve S, et al. Role of Helicobacter pylori screening prior to endoscopy. Eur $f$ Gast Hepatol screening prior

10 Bernersen B, Johnsen R, Bostad L, Straume B, Sommer A Burhol P G. Is Helicobacter pylori the cause of dyspepsia? BrMed f 1992;304:1276-9.

11 Phull PS, Gower JD, Price AB, Green CJ, Jacyna MR $a$ Tocopheral antioxidant levels in chronic gastritis: correlation with mucosal neutrophil infiltration. Gut 1993;34(suppl 1):T133.

12 Crabtree J E, Shallcross T M, Heatley R V, Wyatt J I. Mucosal tumour necrosis factor and interleukin- 6 in patients with Helicobacter pyori associated gastritis. Gut 1991;32:1473-7.

13 Borody T, Andrews P, Mancuso N, Jankiewicz E, Brand S. Helicobacter pylori reinfection 4 years post-eradication (letter). Lancet 1992;339:197. 